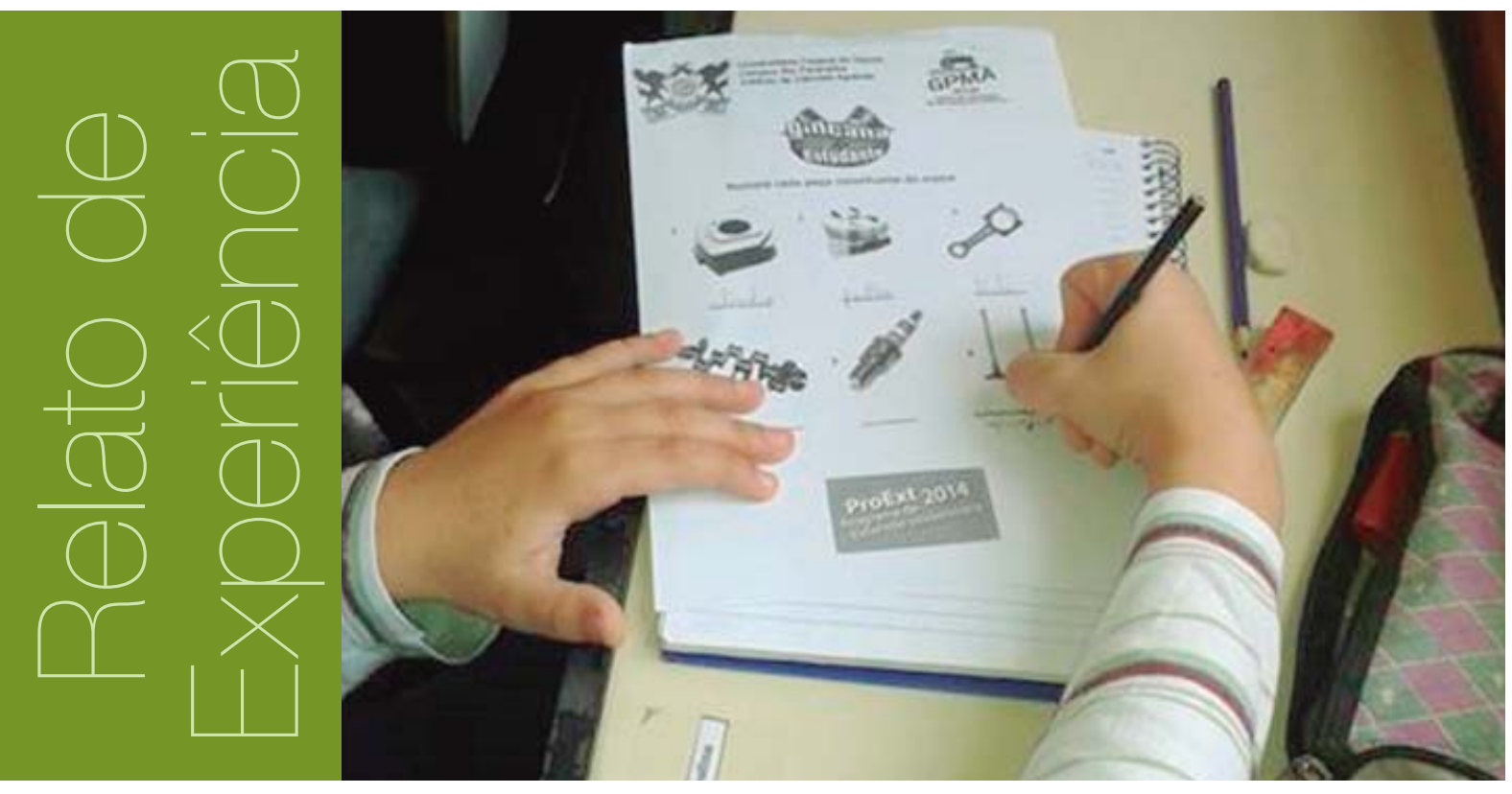

\title{
A mecanização agrícola como instrumento de interação entre discentes de agronomia e alunos do ensino básico
}

Guilherme Andrade Gontijo' - guiandradeagr@gmail.com

Renato Adriane Alves Ruas² - renatoruas@ufv.br

Raí Miranda dos Reis ${ }^{3}$ - rai.reis@ufv.br

João de Deus Godinho Júnior - joao.godinho@ufv.br

Simone Rodrigues Campos Ruas ${ }^{5}$ - simone.ruas@ufv.br

\section{RESUMO}

0 projeto "Alternativa de ensino-aprendizagem na área de mecanização agrícola para estimular e conscientizar alunos do ensino básico e fundamental de Rio Paranaíba-MG" objetivou levar o conhecimento adquirido pelos discentes do curso de Agronomia da Universidade Federal de Viçosa - campus de Rio Paranaíba aos alunos da rede pública de ensino dos municípios Rio Paranaíba e Carmo do Paranaíba. Foram feitas palestras nas escolas municipais e estaduais sobre motores de combustão interna, sua utilização na agricultura e respectivos riscos de acidentes. 0 tema foi bem aceito pelo público, uma vez que se tratava de jovens ligados às atividades agrícolas.

\section{PALAVRAS-CHAVE}

Extensão em mecanização. Segurança na agricultura. Motores de combustão interna. Agricultura.

\footnotetext{
1 Graduando em Agronomia (UFV-CRP). Bolsista do PROEXT 2014.

2 Eng. Agrônomo. Doutor (UFV). Prof. Adjunto III - Mecânica e Mecanização Agrícola UFV-CRP.

3 Graduando em Agronomia (UFV-CRP). Bolsista do PROEXT 2014

4 Graduando em Agronomia (UFV-CRP).

5 Eng. Civil. Mestre (UFV). Prof. ${ }^{a}$ Assistente II - Estruturas Metálicas e Segurança do Trabalho UFV-CRP.
} 


\section{ABSTRACT}

The project "Alternative of teaching-learning in area of mechanization agricultural for stimulate and aware students of basic and fundamental education of Rio Paranaiba-MG" aimed take knowledge acquired by students of course of agronomy of Universidade Federal de Viçosacampus de Rio Paranaíba to students of network public teaching of municipalities Rio Paranaíba and Carmo do Paranaíba. Presentations were made in municipal and state schools about intern combustion engines, their use in agriculture and their risk of accidents. The theme was well received by audience, seeing that they were young linked to agricultural activities.

\section{KEYWORDS}

Extension in mechanization. Safety in agriculture. Internal combustion engines. Agriculture.

\section{Relato de experiência}

Muitos trabalhos são feitos pelas universidades nas áreas da pesquisa e do ensino, porém outra estratégia que fortalece as instituições de ensino superior são as atividades de extensão. Essas três correntes têm de caminhar juntas, cabendo à extensão a busca por disseminar 0 conhecimento para a comunidade que cerca a universidade.

As atividades de extensão visam levar conhecimento e mais qualidade de vida à comunidade, sobretudo aquela circunvizinha à universidade, permitindo uma maior interação entre a sociedade e as instituições de ensino. Iniciativas como essas desenvolvem ações socioeducativas para superar as condições de desigualdade e de exclusão ainda presentes na sociedade (RODRIGUES et al., 2013).

Os projetos de extensão também contribuem consideravelmente no processo de formação dos graduandos, pois, segundo Manchur, Suriani e Cunha (2013), há uma aproximação entre 0 acadêmico e a sociedade, na qual ele adquire experiência e senso crítico em relação às atividades externas ao mundo universitário. Para os docentes que aderem a tais programas também há vantagens, como experiência e complementação curricular.

Nesse contexto, a área da mecanização agrícola torna-se um bom tema de abordagem, uma vez que contribui significativamente para 0 aprimoramento das relações homem-máquinacampo. É necessário que essas tecnologias sejam adotadas de forma correta e segura, incentivando os jovens a se preocuparem mais com o seu cotidiano. Também é preciso alertar os jovens para os possíveis perigos gerados pelas máquinas, por exemplo 0 embuchamento de material vegetal em colhedoras, o qual requer uma recuperação manual (VILELA et al., 2014). Um fator preponderante para evitar acidentes com crianças e jovens é a prevenção por meio de programas educativos sobre medidas de segurança (SOUZA; BARROS0,1999).

Partindo da necessidade de promoção de programas educativos para crianças e jovens, foi desenvolvido pela Universidade Federal de Viçosa - Câmpus Rio Paranaíba (UFV-CRP), de janeiro a dezembro de 2014, o projeto de extensão "Alternativa de ensino-aprendizagem na área de mecanização agrícola para estimular e conscientizar alunos do ensino básico e fundamental de Rio Paranaíba-MG", vinculado ao programa Proext. 0 projeto consistiu em levar conhecimento, por meio de palestras, sobre motores de combustão interna, sua utilização na agricultura e os riscos de acidentes devido ao uso inadequado, aos alunos das escolas públicas dos municípios Rio Paranaíba e Carmo do Paranaíba.

0 Grupo de Pesquisa em Mecanização Agrícola (GPMA) conduziu o programa. Foram envolvidos nesta proposta três alunos de graduação em Agronomia e o professor doutor coordenador da proposta, todos da UFV-CRP. Os estudantes e 0 coordenador foram treinados para realizar as apresentações nas escolas e demais atividades referentes ao projeto.

No primeiro semestre de 2014, a apresentação foi planejada e estruturada. No segundo semestre do mesmo ano, foram realizadas as apresentações nas escolas públicas, sempre agendadas previamente com os responsáveis pela Direção. Participaram das atividades alunos do sexto ano do ensino fundamental ao primeiro ano do ensino médio, em sua maioria residentes na zona 
rural que tinham, no cotidiano, contato com as máquinas apresentadas nas palestras. Isto fez com que os alunos mostrassem muito interesse pelo tema e interagissem com os palestrantes.

Durante as apresentações, dois palestrantes revezaram na explicação do conteúdo exposto por meio de projeção multimídia. Após as explicações, foram feitas gincanas de desfecho, nas quais os grupos de alunos que obtiveram mais acertos relativos aos nomes das peças dos motores de combustão interna ganharam prêmios. Essa atividade estimulou os alunos a realmente aprenderem sobre o conteúdo da palestra, fazendo com que ela se tornasse menos maçante e mais atraente (Figura 1).

0 projeto foi avaliado pelos professores das escolas públicas que também assistiram às apresentações. Esta avaliação foi feita por meio de questionário composto por 20 questões, no qual foi medida a satisfação em relação aos quesitos principais do programa, atribuindo nota de cinco a dez.

Como a cidade de Rio Paranaíba possui poucas escolas de ensino fundamental e médio, o projeto foi estendido para a cidade vizinha, Carmo do Paranaíba, onde foram apresentadas mais três palestras. No total, foram feitas 15 apresentações em cinco escolas, sendo quatro em Rio Paranaíba e uma em Carmo do Paranaíba. Assistiram às palestras 551 alunos e 23 professores.

Por meio das respostas dos questionários, podemos observar que o tema máquinas agrícolas teve grande aceitação pelo público, uma vez que a maioria dos estudantes reside na zona rural (Gráfico 1). Quando à frequência de eventos de extensão nas escolas públicas, os professores atribuíram notas baixas (Gráfico 2), evidenciando a carência de projetos voltados à interação entre universidades e escolas de ensino básico.

Figura 1: Esquerda: Palestra sendo realizada. Direita: Alunos participando da gincana.
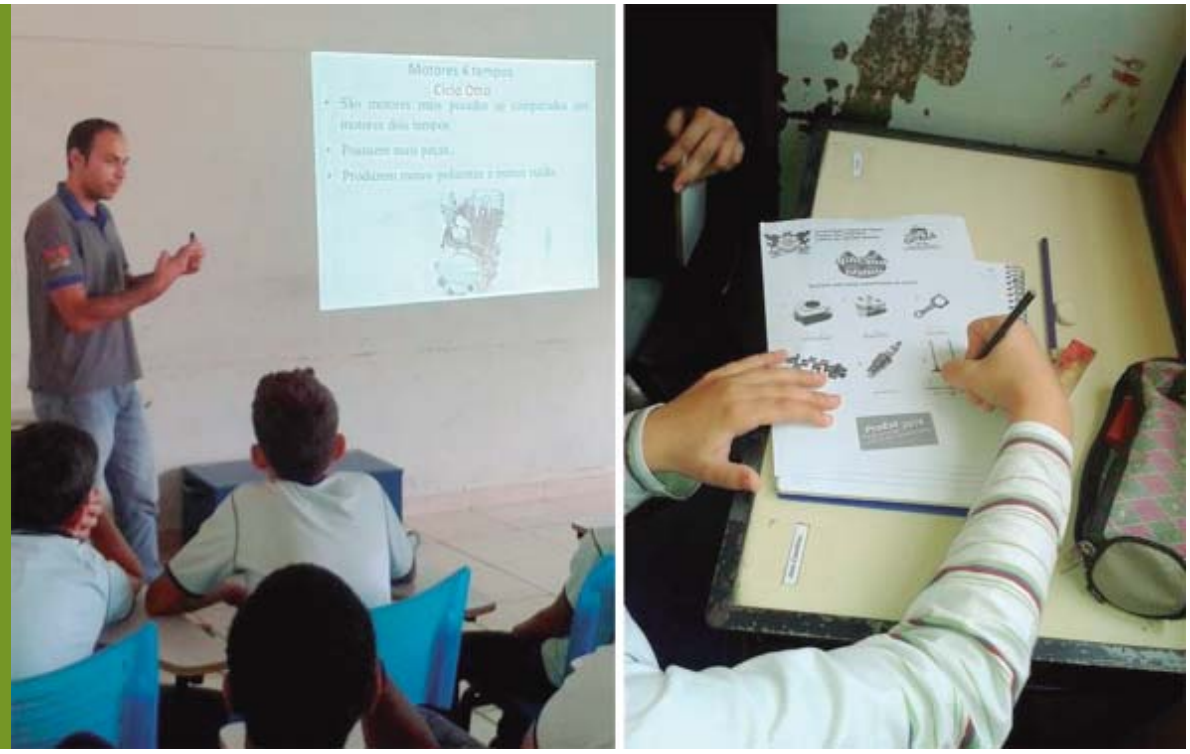

Grafico 1: A proposta do programa foi conivente com 0 cotidiano dos alunos.

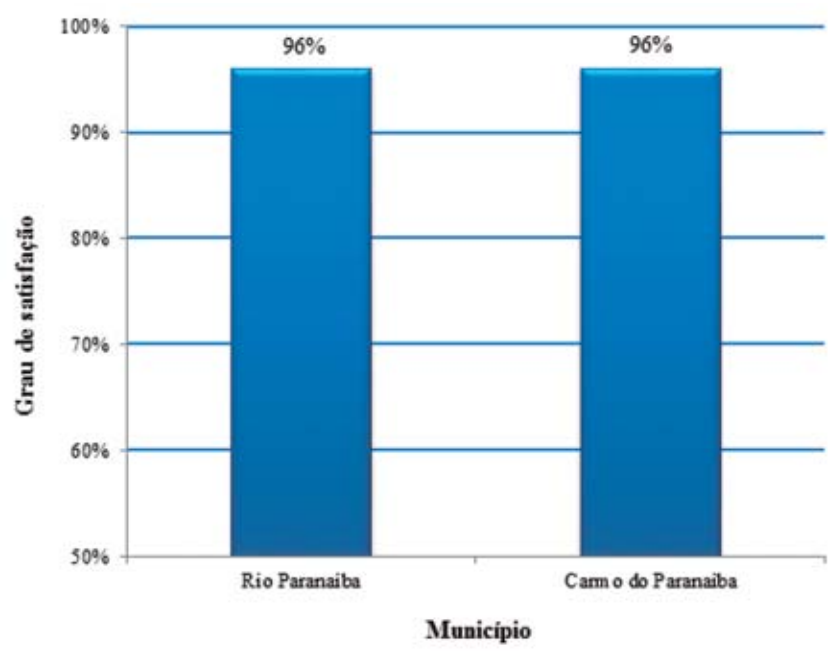




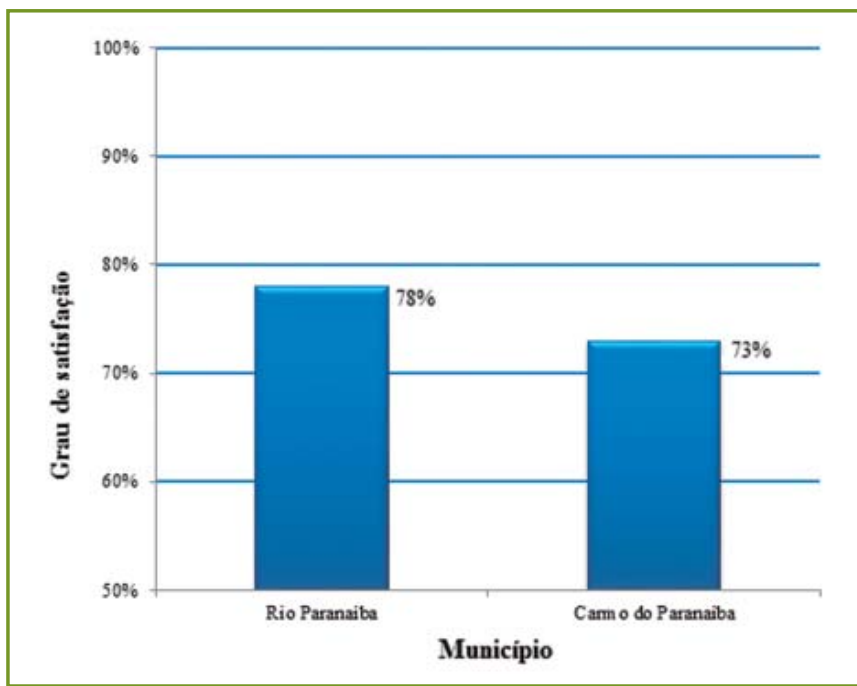

Grafico 2: Eventos como este

ocorrem com a frequência

necessária no cenário educacional.

Fonte: Dados desta pesquisa.

Enfim, o Proext 2014 foi muito profícuo, pois permitiu levar conhecimento aos alunos e também aos professores da rede pública de ensino de dois municípios, além de contribuir significativamente com a formação dos graduandos em Agronomia envolvidos no projeto. Estes adquiriram desenvoltura ao lidar com o público, característica importante na construção de novos profissionais. Devido ao sucesso do Proext 2014, outro projeto de extensão está sendo desenvolvido pelo GPMA em 2015, desta vez buscando levar conhecimento sobre Tecnologia de Aplicação de Agrotóxicos aos operadores de pulverizadores da região do Alto Paranaíba.

\section{Referências}

MANCHUR, Josiane; SURIANI, Ana Lucia Affonso; CUNHA, Márcia Cristina da. A contribuição de projetos de extensão na formação profissional de graduandos de licenciaturas. Revista Conexao UEPG, Ponta Grossa, v. 9, n. 2, p.334-341, jul./dez. 2013.

RODRIGUES, Andréia Lilian Lima et al. Contribuições da extensão universitária na sociedade. Cadernos de Graduação: Ciências Humanas e Sociais, Aracaju, v. 1, n. 16, p.141-148, mar. 2013.

SOUZA, Luiza Jane Eyre Xavier de; BARROSO, Maria Grasiela Teixeira. Revisão bibliográfica sobre acidentes com crianças. Rev. Esc. Enf. USP, [s. L.], v. 33, n. 2, p.107-112, jun. 1999.

VILELA, Rodolfo Andrade de Gouveia et al. Experiência de vigilância no setor canavieiro: desafios para interromper a "maratona" perigosa dos canaviais. Ciênc. Saúde Coletiva, [s...], v. 19, n. 12, p.4659-4668, 2014. 